\title{
El nuevo camino del sur: \\ las migraciones colombianas hacia Argentina ${ }^{1}$
}

\section{The New Road to the South: Colombian Migrations to Argentina}

Enrique Serrano López

Universidad del Rosario, Colombia ORCID: https://orcid.org/oooo-0001-9340-3236

Fecha de recepción: 5, mayo, 2017

Fecha de publicación: 30, agosto, 2017

\section{Resumen}

A lo largo de los últimos quince años, las migraciones colombianas al exterior experimentaron una expansión geográfica sin precedentes. Dentro de este fenómeno, se destaca el fortalecimiento de los flujos migratorios hacia países de América Latina, dentro de los que se destaca Argentina. Por tanto, el principal objetivo de este trabajo es estudiar el origen y la evolución de las migraciones colombianas hacia Argentina y comprender tanto las condiciones estadísticas como etnográficas estudiadas. A pesar de la decreciente tendencia migratoria hacia este país, la experiencia colombiana en Argentina es una fiel evidencia de los nuevos procesos de transformación de las tendencias históricas de migración de esta población.

\section{Palabras Clave}

migraciones; Colombia; Argentina; América Latina

\section{Abstract}

Throughout the last 15 years, Colombian migrations experimented a massive geographical expansion without precedents. Within Latin America, Argentina stands out as the main destination, and therefore, the main objective of this paper is to analyze the origins and evolution of Colombian migrations to Argentina. Resorting to statistical and ethnographical elements, the paper shows the new migratory patterns of Colombian population to Argentina, even though the current migratory trend towards this country is descending.

\section{Keywords}

migrations; Colombia; Argentina; Latin America

doi:10.11144/Javeriana.papo23-1.ncmc

*Autor de correspondencia: sebastian.polo@urosario.edu.co 


\section{Cómo citar este artículo:}

Polo-Alvis, S. y Serrano-López, E. (2018). El nuevo camino del sur: las migraciones colombianas hacia Argentina. Papel Político, 23(1), 131-158. https://doi.org/10.11144/Javeriana. papo23-1.ncmc 


\section{Introducción}

La historia de América es un relato escrito por migrantes. Desde su descubrimiento, la exploración, conquista y dominio de los vastos territorios americanos implicaron un gran esfuerzo humano de migración y poblamiento realizado por grandes poderes europeos como España, Portugal, el Reino Unido y Francia, evento del cual sus efectos se siguen percibiendo hasta el día de hoy. A pesar de que cada uno de estos poderes desarrollaron estos procesos migratorios de la mano de unos intereses políticos, económicos y sociales determinados, las diversas corrientes que alimentaron el proceso de poblamiento del continente serían la semilla del futuro de nuevas relaciones políticas que se darían en las venideras repúblicas del continente. En la América hispánica, los procesos de independencia no solo darían apertura a un proceso de debate y reflexión sobre sus respectivos proyectos de nación, sino que también implicarían definir una concepción de territorio, de población y de soberanía definida. Acontecimientos como la instauración de ciertas formas de Estado, el advenimiento de guerras, los desmembramientos de territorio, las luchas internas, entre otros elementos, hacen parte de una amalgama de elementos que configuraría la realidad actual de las repúblicas hispanoamericanas.

Dentro de las múltiples experiencias de definición de la nacionalidad en América Latina, Argentina es un caso simbólico en la reunión. Tras un largo y turbulento proceso de construcción política y social, dentro de la realidad argentina hubo un acontecimiento de transversal importancia para el desarrollo histórico de este país: las migraciones. La importancia migratoria de este país ha influido directa y tangencialmente en los diversos procesos de transformación política y social de otros países de la región y del mundo. Desde acontecimientos icónicos como la diáspora paraguaya, boliviana y peruana, el exilio político chileno y uruguayo, hasta la recepción humanitaria de refugiados yugoslavos, sirios, afganos, han sido de gran importancia dentro de la actualidad migratoria argentina. Sin embargo, durante los últimos treinta años, dos fenómenos migratorios de gran importancia han venido siendo un elemento que ha incidido en el surgimiento de nuevas tendencias migratorias de peso dominante en la región: las migraciones venezolanas y, para el exclusivo interés de este artículo, las migraciones colombianas.

Con la creciente importancia de Argentina como destino de gran atracción para los migrantes prospectivos, al igual que el rol desempeñado en labores de adopción de refugiados, el propósito de este artículo se basa en estudiar la evolución y la proyección de las migraciones colombianas hacia Argentina a lo largo de los últimos treinta años. Para este objetivo, se realizará una revisión somera de la historia migratoria de Argentina, para luego identificar la naturaleza y la evolución de las migraciones colombianas hacia este destino durante los últimos veinticinco años, en adición con elementos que van desde las condiciones propias de los migrantes hasta su dispersión a lo largo del territorio 
argentino. Por último, se pretende realizar una reflexión sobre la experiencia migratoria colombiana en Argentina acorde con su contexto migratorio y su testimonio de vida.

\section{"Gobernar es poblar"}

A lo largo de su historia republicana, Argentina ha sido transversalmente influida por migraciones masivas que cumplieron un papel primordial en la colonización de los vastos territorios de este país, al igual que en la configuración de su dimensión social, económica y política. Las migraciones hacia Argentina de personas provenientes de Europa y de otros países de América Latina se han caracterizado como un fenómeno que ha servido como un referente paralelo de las coyunturas generales fuera del país. Este fenómeno, si bien ha sido profundamente significativo para la sociedad argentina, no ha sido regular en el volumen y la naturaleza de sus flujos, lo que nos motiva a dividir la temporalidad de las migraciones hacia Argentina en cinco fases: prerrepublicana (1816-1853), primera expansión (1854-1913), segunda expansión (1914-1960), contracción (1961-2003) y tercera expansión (2003-2015).

Tras la proclamación de independencia en el Congreso de Tucumán de 1816, durante los primeros cuarenta años los esfuerzos de organización nacional tuvieron que distribuirse en varias urgencias de índole política y militar que amenazaron la integridad del Estado argentino, que varían, desde la sublevación de caudillos provinciales y guerras civiles, hasta la intervención en conflictos internacionales. Durante este turbulento periodo, en el que hubo múltiples cambios políticos y territoriales, siempre estuvo presente la problemática sobre el control y el poblamiento de los vastos territorios argentinos, los cuales estaban habitados por indios hostiles, gauchos rebeldes y delincuentes. De acuerdo con Lynch (1985), citado en Bethell (1985, p. 264), Argentina se independizó “con pocos elementos considerados esenciales en un Estado latinoamericano", en los que "tenía minerales, pero no minas, tierra pero poca mano de obra, comercio pero escasas mercancías".

Estas condiciones, conjugadas con el desarrollo de una campaña libertadora y con un escenario de crisis política y guerra civil que se prolongó a lo largo de los primeros once años de su vida republicana, pusieron en evidencia la importancia del poblamiento de zonas periféricas como forma de control territorial del Estado. Bajo la administración del Primer Triunvirato de la Junta de Gobierno, se promulgó el Decreto del 4 de septiembre de 1812 sobre Inmigración y Colonización, en el cual el Gobierno ofrecía "su inmediata protección a los individuos de todas las naciones y a sus familias que quieran fijar su domicilio en territorio del Estado, asegurándoles el pleno goce de los derechos del hombre en sociedad" (Levene, 1925, p. 226). A partir de esta política, se allanó el camino para el desarrollo de una política migratoria que buscara la colonización de territorios no habitados y, por consiguiente, una activación económica que permitiera representarse en réditos para el Estado. Dentro de las normas que regularizaron el 
proceso migratorio hacia Argentina, se destacan el Decreto de 1813 sobre medidas económicas para evitar el latifundio y las leyes de 1818 y 1819 durante el Directorio de Juan Martín de Pueyrredón, las cuales se enfocaron en la localización de las nuevas colonias en territorios de frontera y "en terrenos baldíos en las provincias de Salta, Cuyo, Jujuy, Santiago del Estero, Catamarca y Córdoba" (p. 227).

Sin embargo, a pesar de la temprana voluntad de las Provincias Unidas del Río de la Plata sobre el incentivo a las migraciones, en las que el sistema de colonización del territorio se estimuló mediante la repartición y administración enfitéutica de la tierra durante la Presidencia de Bernardino Rivadavia (1825-1827), el acrecentamiento de los conflictos políticos internos sobre las alternativas de proyecto de organización nacional entre unitarios y federales dio inicio a una sucesión de sublevaciones internas y al desencadenamiento de la Guerra del Brasil (1825-1828), eventos que condicionaron negativamente el ingreso de nuevos migrantes al separar el territorio de la Banda Oriental del territorio rioplatense.

Estas confrontaciones concluyeron en el establecimiento de una relativa estabilidad política con el primer gobierno bonaerense de Juan Manuel de Rosas (1829-1832), en el que también se concretó el Pacto Federal de 1831, el cual declararía la conformación de la Confederación Argentina. Durante la mencionada Administración, se aumentó el dominio territorial con la Primera Campaña al Desierto de 1833, en la que se fundó la ciudad de Bahía Blanca y se movió la frontera indígena hasta los ríos Neuquén, Limay y Negro, labores que buscaron "contener la agresión india, ampliar la frontera e imponer una paz durable" (Lynch, 1985, citado por Bethell, 1985, p. 266). Durante este periodo, entre 1833 y 1852,

hubo dos grandes corrientes inmigratorias: la francesa y la británica (que incluía a los irlandeses). Los datos estadísticos sobre el crecimiento de las colectividades extranjeras proporcionados por el investigador Benito Díaz, para los años 1842 y 1854 indican: hacia 1842 los franceses eran 12.000, los británicos 8.00o, e italianos y alemanes sumaban 15.00o. En 1854 los franceses alcanzaban los 25.000, los británicos 22.000, los italianos 15.000 y los españoles 20.000 (en especial vascos y canarios). En conjunto, los extranjeros alcanzaban los 82.000 entre la ciudad y el campo. (Oteiza, 2007, p. 6)

Empero, a pesar de estos avances, con el segundo Gobierno de Juan Manuel de Rosas dotado de facultades extraordinarias durante su ejercicio del poder (1835-1852), además de los problemas colaterales que se desenvolvieron con el advenimiento de la Guerra Grande en Uruguay (1836-1851), la Confederación Argentina entró en un episodio de aislamiento internacional, en el que perduraron guerras contra la Confederación Peruano-Boliviana y el Imperio del Brasil, además de los bloqueos portuarios anglofranceses a Buenos Aires y la creciente desconfianza internacional de la figura de Rosas. Como resultado de la violencia política perpetrada por la Mazorca, organización parapolicial 
rosista, los disidentes políticos de Rosas se vieron forzados a migrar a países limítrofes como Uruguay, Chile y Bolivia, en adición con el auge migratorio fomentado desde el Estado en países como Chile y Brasil que se desarrollarían a finales de la década de 1840.

Sin embargo, con el orden constitucional de la Constitución de 1853, la cual mantiene su vigencia hasta el día de hoy, siendo el punto de inicio de la República Argentina, se daría comienzo a un nuevo incentivo institucional al desarrollo de las migraciones con miras a consolidar el dominio territorial y el desarrollo de actividades económicas. Dicha constitución se diseñó a partir de los principios sociológicos de Juan Bautista Alberdi sobre la utilización de la inmigración como herramienta para la consecución del progreso y la civilización (célebre por ser autor de la frase que titula este acápite).

Con el inicio del nuevo orden sociopolítico argentino, se dio apertura a la primera expansión migratoria (1854-1913), en la cual se manifestarían las dos oleadas migratorias más significativas hacia Argentina. Con la implementación de programas de migración vascofrancesa para la colonización agrícola en las provincias de Corrientes y Entre Ríos (Levene, 1925, pp. 440-441), se daría inicio a una política intensiva de inmigración en las inmediaciones de la Presidencia de Justo José de Urquiza (1854-1860). A partir de ello, el número de migrantes aumentó exponencialmente a mediados de las décadas de 1860 y 1870 , a pesar del efímero divorcio entre el Estado de Buenos Aires con el resto del país, saldado posteriormente con la firma del Pacto de San José de Flores en 1860. Como continuación a estas políticas, a pesar de los acontecimientos bélicos de la Guerra de la Triple Alianza (1864-1870), durante la Presidencia de Bartolomé Mitre (1862-1868), se dio continuidad al desarrollo de la colonización del territorio desde la Administración ministerial de Guillermo Rawson, entre las que se destaca la creación de la colonia galesa en el Chubut en 1863, la cual daría fundación a ciudades como Rawson, Trelew y Puerto Madryn.

Sin embargo, a pesar de las iniciativas migratorias desarrolladas por Urquiza y Mitre, el primer auge migratorio se daría en las inmediaciones de las presidencias de Domingo Fausto Sarmiento (1868-1870) y de Nicolás Avellaneda (1874-1880). Con la realización del primer censo nacional en 1869, se registró la presencia de 298854 extranjeros, los cuales representaban el 12,1 \% del total de la población en Argentina; cifras que son reflejo de los avances de las políticas migratorias anteriores a este primer registro censal. Posterior a este ejercicio censal, se desarrolló la promulgación de la Ley Nacional 817 de 1876 sobre fomento a la inmigración, que buscó “promover las inmigraciones europeas al país, en consonancia con el espíritu que prevaleció en la primera Constitución Nacional Argentina de 1853" (Maurizio, 2006, p. 10). Esta tendencia también se fortaleció por la Segunda Conquista del Desierto realizada en la Presidencia de Julio Argentino Roca (1880-1886), la cual permitió un mayor control territorial del Estado argentino sobre los territorios de la Patagonia y del Chaco austral, que generó nuevas zonas para el desarrollo de la migración tras la mitigación de la amenaza militar india a las ciudades periféricas. 
Es en el periodo posterior a este primer hito estadístico en el que se desarrolla una profunda expansión de la inmigración en Argentina entre 1870 y 1913. De acuerdo con el censo de 1895, la población extranjera en territorio argentino se calculó en 1005427 personas, lo que evidenció un crecimiento porcentual del 236,4 \% en comparación con los registros de 1869 (véase tabla 1). Este incremento se dio gracias a un periodo de rápido crecimiento económico en el que "todos los indicadores señalan una tasa media de crecimiento anual de más del 5 \% a lo largo de tres decenios" (Cortés, 1985 , citado por Bethell, 1991, p. 38).

\section{Tabla 1}

\section{Evolución histórica de la población extranjera en Argentina (1869-2010)}

\begin{tabular}{|c|c|c|c|c|c|c|c|}
\hline 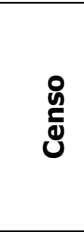 & 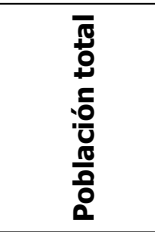 & 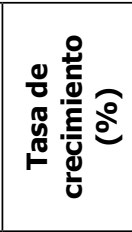 & 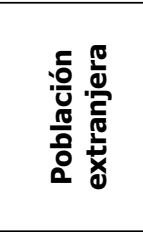 & $\begin{array}{l}\text { 은 } \\
\text { 응 } \\
\text { 응 }\end{array}$ & 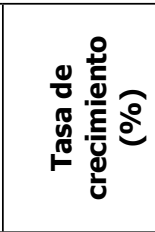 & 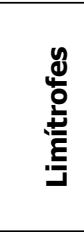 & 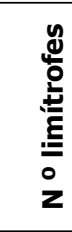 \\
\hline 1869 & 1531360 & - & 298854 & 12,1 & - & 19,7 & 80,3 \\
\hline 1895 & 2950384 & 92,6 & 1005427 & 25,4 & 236,4 & 11,5 & 88,5 \\
\hline 1914 & 5527285 & 87,3 & 2378217 & 29,9 & 136,5 & 8,5 & 91,5 \\
\hline 1947 & 15893811 & 187,5 & 2435927 & 15,3 & 2,4 & 12,9 & 87,1 \\
\hline 1960 & 20013793 & 25,9 & 2607447 & 13 & 6,9 & 17,9 & 82,1 \\
\hline 1970 & 23364431 & 16,7 & 2210400 & 9,5 & -152 & 24,1 & 75,9 \\
\hline 1980 & 27947446 & 19,6 & 1903159 & 6,8 & -139 & 39,6 & 61,4 \\
\hline 1991 & 32615528 & 16,7 & 1615473 & 5 & -152 & 52,1 & 47,9 \\
\hline 2001 & 36260130 & 11,1 & 1517904 & 4 & -61 & 60,3 & 39,7 \\
\hline 2010 & 40091359 & 10,5 & 1805957 & 4,5 & 189 & 68,9 & 31,1 \\
\hline
\end{tabular}

Fuente: Elaboración propia a partir de informes censales históricos del Instituto Nacional de Estadísticas y Censos (Indec).

Este progreso económico se caracterizó por estar basado en el incremento de flujos de capital y en la "explotación de productos básicos como los agrícolas y pecuarios que encontraban una salida en los mercados internacionales" (Cortés, 1985, citado por Bethell, 1991, p. 39), los cuales fueron motores de crecimiento para el desarrollo de otros sectores de la economía, caracterizados por el surgimiento de "industrias nacionales de construcción de viviendas, elaboración de alimentos y bebidas, y producción de textiles, cuya ubicación y relativa ventaja dependían de la proximidad de los mercados, de costos de transporte más bajos y, en el caso de la alimentación, del costo inferior de la materia prima local”. De esta gran masa de inmigrantes, la mayoría "provenían de Europa Mediterránea -Italia y España- conjunto que en 1914 representaba el 92 \% del total de extranjeros residiendo en el país” (Maurizio, 2006, p. 7) (véase tabla 2), aunque 
también destacan migrantes franceses, alemanes, suizos, neerlandeses expulsados de Sudáfrica por las guerras bóeres, entre otros.

\section{Tabla 2}

\section{Comparación de población extranjera en Argentina por nacionalidades (1869-1914)}

\begin{tabular}{|l|l|l|l|l|l|}
\hline Censo 1869 & $\mathbf{2 9 8} \mathbf{8 5 4}$ & Censo 1895 & $\mathbf{1 ~ 0 0 5 ~ 4 2 7}$ & Censo 1914 & $\mathbf{2 ~ 3 7 8 ~ 2 1 7}$ \\
\hline Italia & 71442 & Italia & 492836 & Italia & 929863 \\
\hline España & 34080 & España & 198685 & España & 829701 \\
\hline Francia & 32383 & Francia & 94698 & Rusia & 93634 \\
\hline Uruguay & 15206 & Uruguay & 48656 & Uruguay & 86428 \\
\hline Chile & 10911 & Brasil & 24725 & Francia & 79491 \\
\hline Reino Unido & 10709 & Reino Unido & 21788 & Imperio otomano & 64369 \\
\hline Bolivia & 6200 & Chile & 20594 & $\begin{array}{l}\text { Imperio } \\
\text { austrohúngaro }\end{array}$ & 38123 \\
\hline Brasil & 6065 & Alemania & 17143 & Brasil & 36442 \\
\hline Suiza & 5860 & Rusia & 15047 & Chile & 34217 \\
\hline $\begin{array}{l}\text { Alemania del } \\
\text { Norte }\end{array}$ & 4997 & Suiza & 14789 & Paraguay & 28049 \\
\hline
\end{tabular}

Fuente: Elaboración propia a partir de registros censales de 1869, 1895 y 1914 del Indec.

Como continuación de este periodo de expansión económica, con los registros resultantes del censo de 1914, se percibió que la cifra de inmigrantes en territorio argentino ascendió a 2378 217, calculado en un crecimiento porcentual del 136,4 \%. Este incremento también fue el resultado de la expansión económica desarrollada en los nuevos territorios del sur de Argentina, en los que, no solo se desenvolvía una colonización agroexportadora, sino también se daban los primeros pasos hacia la explotación de hidrocarburos encontrados en "Comodoro Rivadavia, en la Patagonia, así como en Neuquén, Mendoza y Salta” (Rock, 1985a, citado por Bethell, 1991, p. 110).

La tercera fase de la historia migratoria argentina se desarrollaría en un periodo de alta convulsión política al nivel internacional con el advenimiento de las dos guerras mundiales, acontecimientos que influenciaron profundamente en una segunda expansión de las migraciones hacia Argentina. Si bien las confrontaciones bélicas mencionadas significaron una reducción de los flujos de capital entrantes al mercado argentino que afectó su atractivo como destino de migración laboral por sus elevados índices de desempleo, "entre 1919 y 1923 Argentina volvió a experimentar tasas de crecimiento anuales elevadas del orden del $8 \%$, a pesar de la reducción del nivel de capitales" (Maurizio, 2006, p. 11). A pesar de esta leve recuperación, durante la Segunda Guerra Mundial, "la tasa neta de inmigración de estos años fue, en promedio, cercana al $4 \%$, pero sobre 
una tendencia claramente decreciente", condicionada por la existencia de un mercado laboral en el que "la falta de trabajo, la caída en los niveles salariales y el aumento del costo de vida fueron características del mercado laboral durante estos años" (p. 12).

A pesar de que el periodo de entreguerras se caracterizó por una transformación política caracterizada por un progresivo aislamiento internacional como resultado de una alta presión diplomática de los Estados Unidos por el mantenimiento de la neutralidad argentina contra el Eje hasta 1944 (Rock, 1985b, citado por Bethell, 1991), durante la década peronista se volvió a percibir un repunte de las migraciones hacia Argentina en conjugación con las migraciones masivas de europeos hacia América tras la Segunda Guerra Mundial. Pero, a pesar de la prosperidad económica que gozó Argentina, materializada en la "expansión del gasto público, reforzando el papel del Estado en la producción y la distribución; la alteración de los precios relativos para fomentar una distribución más igualitaria de la renta nacional; y el progresivo establecimiento de un sistema de incentivos al mercado interno" (Torres y De Riz, 1985, citado por Bethell, 1991, p. 38), las migraciones no alcanzaron proporciones iguales a las de las oleadas anteriores debido al retraso que empieza a experimentar la economía argentina, representado en un "proceso de continua reducción de los incentivos para migrar hacia el país" (Maurizio, 2006, p. 13). Sin embargo, es en los censos de 1947 y 1960 en los que se perciben los registros más altos de presencia de migrantes en Argentina, calculados en 2435927 y 2604 447, respectivamente, a pesar de la profunda ralentización porcentual del crecimiento de la población inmigrante, en la que solo creció un 2,4 \% para 1947 y un 6,9 \% para 1960 (véase tabla 1).

La cuarta fase de la historia migratoria argentina está directamente marcada por el progresivo deterioro de las instituciones democráticas en Argentina, resultado del derrocamiento de Perón en 1955, la revolución libertadora de 1966 y del golpe de Estado de 1976 en el que los flujos migratorios hacia Argentina sufrieron una transformación contracíclica, resultado de una política de terror de Estado y de persecución política que limitó el transcurso normal de la vida de los ciudadanos, además de un deterioro económico y de un cierre de fronteras a la migración como medida ante la posible entrada del comunismo. En similitud con casos como el chileno y el uruguayo, las tendencias históricas de migración tendieron a revertirse, al ser el episodio de mayor exilio de argentinos, en el que durante la década de 1970 "fueron 339.329 los individuos que salieron del país", dispersados en países como "México y España, y en menor medida a Suecia, Francia, Venezuela, Brasil, Bélgica, Holanda y Estados Unidos” (González, 2009, pp. 3-4).

Dentro del mencionado periodo, las migraciones de europeos hacia Argentina se redujeron con diversas legislaciones desarrolladas tanto en tiempos de dictadura (Ley de Migraciones de 1981) como dentro del proceso de transición a la democracia (leyes migratorias de 1985 y 1987). A su vez, las migraciones provenientes de países limítrofes como Bolivia, Paraguay y Chile incrementarían como resultado de escenarios de 
inestabilidad política condicionados por dictaduras y crisis económicas. Acorde con la crisis económica que acarreó Argentina a lo largo de la década de 1990, teniendo su epítome con la crisis de 2001, las cifras del total de inmigrantes en territorio argentino llegaron a su punto más bajo en el siglo XX, que registraron 1615473 para 1991 y 1517904 para 2001, y representó una contracción porcentual del 15,2 y del $6.1 \%$, respectivamente (véase tabla 1 ).

\section{El colombiano en los nuevos tiempos de un destino decimonónico}

Tras la dimisión de Fernando de la Rúa en 2001 y de las presidencias interinas de Adolfo Rodríguez Saa, Eduardo Caamaño y Eduardo Duhalde, Néstor Kirchner llega a la Presidencia en 2003, con lo cual se dio inicio a un punto de giro de las políticas de Estado referentes a la migración. Dentro de las gestiones gubernamentales, se destaca la promulgación de la Ley 25.871/2003, de 17 de diciembre, la cual "cambia el paradigma del abordaje de la cuestión migratoria, pasando de la defensa de la soberanía nacional y la seguridad interior a partir de la protección de fronteras [...], a la integración del migrante a la sociedad de recepción, mediante el reconocimiento y tutela de sus derechos" (Organización Internacional para las Migraciones [OIM], 2012c, p. 13). Dicha ley estaría directamente influida por los nuevos procesos de integración económica al nivel regional, que acogió el Acuerdo sobre Residencia para los Nacionales de los Estados Partes del Mercado Común del Sur (Mercosur), en el que no solo vinculaba a los Estados miembros, sino también a los Estados asociados como Bolivia, Perú, Ecuador, Venezuela y Colombia (OIM, 2012c).

De la mano con estos nuevos tiempos de las migraciones, en el caso colombiano, las migraciones hacia Argentina se han desarrollado como un fenómeno reciente, el cual ha sido paralelo a una expansión masiva del número de migrantes durante la última década. Según Palma (2015), a lo largo de la tercera ola migratoria de colombianos que se desarrolló a mediados de la primera década del siglo XXI, se dio inicio a un proceso de diversificación de destinos, lo cual conllevó "la extensión de la diáspora hacia Europa, especialmente a España, así como a lugares no tradicionales en América Latina” (Echeverri, 2005, citado por Palma, 2015, p. 12).

Como resultado de este proceso, la migración de colombianos hacia Argentina experimentó un crecimiento exponencial durante los últimos diez años. Según los registros censales del Indec de 2001 (véase tabla 3), residían 3713 personas nacidas en Colombia en territorio argentino, el cual se traduce en un aumento del $40 \%$ a lo largo de la década de 1990. Sin embargo, la dimensión del fenómeno sería mucho más profunda. Según el Indec (véase tabla 3), para 2011, se registra la presencia de 17576 connacionales, lo cual significa que, en comparación con los registros de 2001, se experimentó un aumento sustancial del $373 \%^{2}$. Este aumento se deriva, principalmente, de las nuevas legislaciones argentinas 
referentes a la inmigración, lo cual generó una ventana de oportunidad para el fortalecimiento de la presencia de poblaciones migrantes provenientes de países limítrofes, en detrimento del peso de las históricas colonias europeas asentadas desde el siglo XIX.

Empero, a pesar de que a lo largo de la primera década del siglo XXI los gobiernos Kirchner experimentaron un aumento sustancial de las exportaciones agrícolas, durante los siguientes diez años las condiciones económicas del país se deteriorarían como resultado de un avance progresivo de la inflación resultante de un constante gasto público enfocado en la subvención de múltiples servicios públicos y actividades económicas, además de una restricción a las exportaciones y a la libre circulación de divisas. Si bien estos incentivos repercutieron directamente en un crecimiento del número de inmigrantes en Argentina según los registros de 2010 (véanse tablas 1 y 3), las consecuencias económicas de la crisis financiera de 2014 comenzarían a reconfigurar las tendencias migratorias de las diversas nacionalidades migrantes. Con la llegada de Mauricio Macri a la Presidencia del país en 2015, diversos hechos que influyeron en el contexto económico de la sociedad argentina, como el progresivo desmontaje de los sistemas de subsidios a los servicios públicos y al consumo y la liberación del cepo cambiario a las divisas, generaron un progresivo encarecimiento del costo de vida, lo cual puede dar explicación a una reversión de la tendencia de las migraciones colombianas hacia Argentina de la última década (véase tabla 3).

Considerando que Argentina es el país de mayor recepción de migrantes provenientes de países de la región en América del Sur durante la última década (OIM, 2012a, 2012b), es necesario mencionar que la transformación de la tendencia migratoria de la población colombiana entre 2010 y 2015 es algo que vale la pena destacar, teniendo en cuenta la tendencia al alza de las migraciones en general hacia este país (véase tabla 3 ). Para 2015, se estima la presencia de 8640 colombianos, lo cual resalta una baja sustancial en comparación con los registros de 2010. Sin embargo, antes de indagar mediante una revisión etnográfica las condiciones migratorias de los colombianos en Argentina, es preciso comprender los elementos tendenciales de distribución territorial, ubicación laboral y flujos migratorios y de remesas de esta población. 
Tabla 3

Composición por país de nacimiento de la población migrante en Argentina (1991-2015)

\begin{tabular}{|c|c|c|c|c|c|c|c|}
\hline 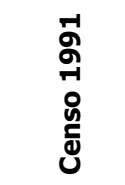 & 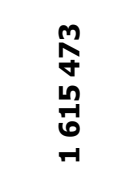 & 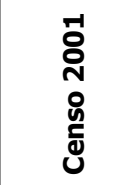 & 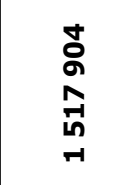 & 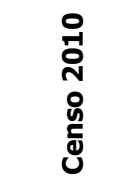 & 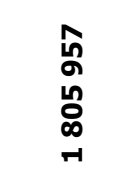 & 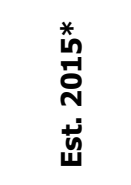 & $\begin{array}{l}\text { D̃ } \\
\text { M } \\
0 \\
0 \\
0 \\
\text { N }\end{array}$ \\
\hline Italia & 328055 & Paraguay & 322962 & Paraguay & 550713 & Paraguay & 679044 \\
\hline Paraguay & 251130 & Italia & 216030 & Bolivia & 345272 & Bolivia & 419048 \\
\hline España & 224081 & Bolivia & 231789 & Chile & 191147 & Chile & 213119 \\
\hline Chile & 218217 & Chile & 211093 & Perú & 157514 & Perú & 195320 \\
\hline Bolivia & 143735 & España & 133614 & Italia & 147499 & Italia & 152338 \\
\hline Uruguay & 133653 & Uruguay & 116672 & Uruguay & 116592 & Uruguay & 132749 \\
\hline Brasil & 33543 & Perú & 87546 & España & 94030 & España & 98050 \\
\hline Polonia & 28819 & Brasil & 33748 & Brasil & 41330 & Brasil & 48792 \\
\hline Perú & 15977 & Polonia & 13671 & $\begin{array}{l}\text { Estados } \\
\text { Unidos }\end{array}$ & 19147 & China & 14397 \\
\hline Alemania & 15302 & Alemania & 9913 & Colombia & 17576 & Colombia & 8640 \\
\hline
\end{tabular}

Fuente: Elaboración propia a partir de información censal del Indec compilada por la Comisión Económica para América Latina (Cepal) (2016) y de información de la Organización de las Naciones Unidas (2017).

La población colombiana en Argentina ha tendido a ubicarse en los principales centros urbanos dentro de este país, en el que la predominancia de la Ciudad Autónoma de Buenos Aires como lugar de residencia resalta sobre las demás provincias, donde se localizan 9619 colombianos (el 54,7 \% del total), según registros del Indec de 2010 (Cepal, 2016) (véase figura 1). No obstante, es necesario mencionar también la tendencia de la migración colombiana a asentarse en provincias dentro de la región del litoral argentino, al igual que en el interior. De esos casos, destaca la presencia de connacionales en provincias como Buenos Aires (3932, 22,3 \%), Córdoba (791, 4,5 \%), Santa Fe (713, 4 \%), Mendoza (590, 3,3 \%) y Entre Ríos (229, 1,3 \%). De lo anterior, es posible afirmar que las tendencias de dispersión territorial de las migraciones colombianas en Argentina obedecen directamente a la búsqueda de los principales centros económicos del país, desentendiéndola de particularidades migratorias y de lógicas distintas como migraciones fronterizas, migración por colonia, entre otros. Además, según información de la OIM (2012d, p. 29), la forma de entrada de colombianos a Argentina es la vía aérea, en la que para 2014 alcanzó el 58 \% de los flujos migratorios de personas con radicación permanente en el país, seguida de la vía terrestre con el $27 \%$ y la vía marítima con el $15 \%$. 
Figura 1

\section{Dispersión territorial de la población colombiana en Argentina en $\mathbf{2 0 1 0}$}

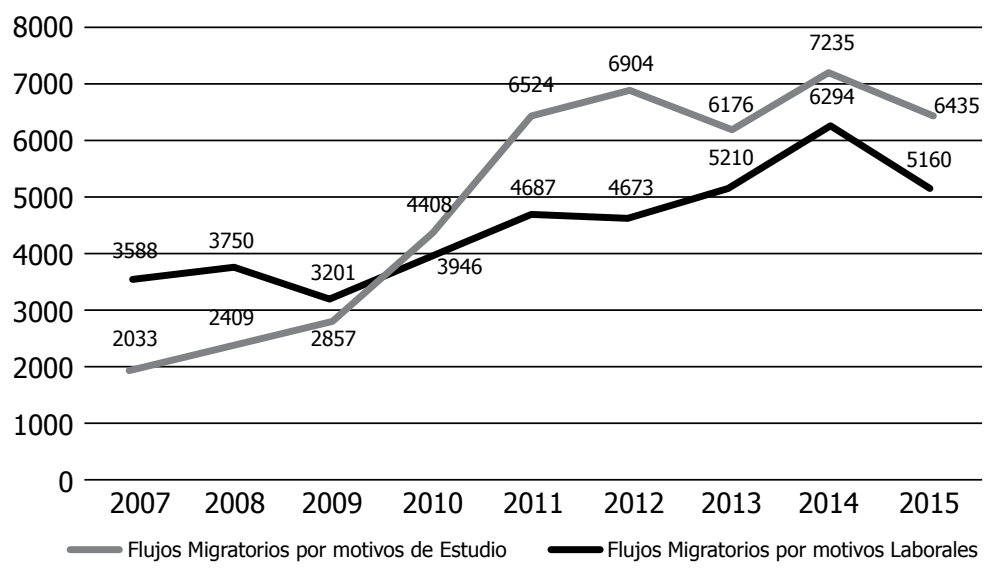

Fuente: Elaboración propia a partir de la Cepal (2016).

Teniendo en cuenta los postulados expuestos, es posible ver que los flujos migratorios de colombianos hacia Argentina, en concordancia con las cifras oficiales del Indec, han tendido al alza durante los últimos diez años, a pesar de percibir un reciente descenso en los registros de 2015 (véanse figura 2 y tabla 3). Si bien la tendencia dominante obedece a intereses de corte educativo, es posible ver que tanto las variaciones tendenciales como el volumen del número de flujos migratorios tienden a ser parejos entre 2013 y 2015 (véase figura 2). El fortalecimiento de los flujos migratorios laborales no solo corresponde a un auge migratorio resultante de la tercera ola migratoria que se desarrolló a inicios de la primera década del siglo XXI, sino también al creciente atractivo de Argentina como destino estudiantil y laboral para los migrantes. Además, es de vital importancia resaltar que este aumento sustancial de la población colombiana no obedece a patrones ligados directamente con el conflicto armado, a pesar de que los tiempos de migración de la tercera ola coinciden paralelamente con el avance de combates entre fuerzas del Estado colombiano y grupos irregulares tras el fracaso de los diálogos del Caguán de 2002, al igual que la activa participación de Argentina en el Programa de Reasentamiento Solidario de refugiados del Alto Comisionado de las Naciones Unidas para los Refugiados (Acnur) suscrito en 2004. Si bien se registraron 3432 refugiados para 2016 (Acnur, 2016), para los cuales se percibió un índice de permanencia del $65 \%$ para estas poblaciones radicadas en territorio argentino (Acnur, 2015, p. 11), solo se registraron 542 refugiados de nacionalidad colombiana para el mismo año, lo cual representa una cifra bastante inferior con relación a las tendencias migratorias dominantes. 
Figura 2

Evolución de los flujos migratorios de colombianos hacia Argentina por motivos de estudio y laborales (2007-2015)

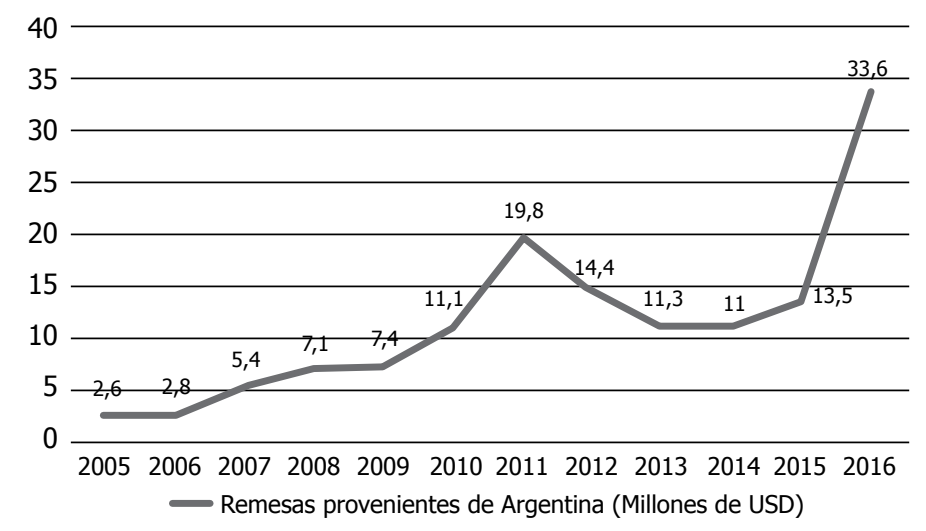

Fuente: Elaboración propia a partir de información provista por la Unidad Administrativa Especial Migración Colombia otorgada por vía derecho de petición (2017).

Ahora bien, partiendo de estas condiciones, la evolución de las tendencias migratorias va de la mano de la evolución de los flujos migratorios de colombianos hacia Argentina, en la que se logra percibir una progresiva ralentización del crecimiento de estos movimientos entre 2011 y 2015, a pesar de los repuntes percibidos en 2012 y 2014 (véase figura 2). Es de clara importancia resaltar la creciente perspectiva de los migrantes colombianos sobre el gran atractivo que tiene Argentina como destino educativo, en el que es de gran incentivo para los migrantes "el acceso, permanencia y modalidad de inserción en la educación, principalmente, superior argentina”, la cual se da como consecuencia de que el "sistema educativo colombiano fue arancelado, es decir, si bien es público el mismo no es gratuito" (OIM, 2012d, p. 41). Se estima que el número preciso de estudiantes colombianos que cursan o cursaron un tercer nivel educativo (superior no universitario, universitario y posuniversitario) asciende a 11570 personas, de los cuales 5244 eran estudiantes de educación superior para 2010 (Cepal, 2017).

No obstante, a pesar de la gran importancia que ha tomado la educación como factor de atracción para los colombianos migrantes, es también necesario resaltar la creciente importancia de los factores laborales como un componente clave en el desarrollo del fenómeno migratorio. De acuerdo con la OIM (2012d, p. 60), el $47 \%$ de los colombianos en Argentina sostienen su estadía mediante su fuerza laboral, población que, según registros censales de 2010, se calcula en 10428 colombianos que se declaran como económicamente activos (véase tabla 4). De esa población, se resalta la alta participación en rubros económicos específicos del sector de servicios como los servicios comunales, 
sociales y personales con 3059 personas registradas para 2010, seguido del sector del comercio, restaurantes y hoteles con 2005 y el sector de establecimientos financieros, seguros y servicios con 1556 (Cepal, 2016) (véase tabla 5). A pesar de que el $78 \%$ de colombianos tienden a durar menos de tres años en sus trabajos (OIM, 2012d, p. 56), es notable el reciente incremento de divisas provenientes de Argentina, en las cuales se pasó de registrar USD 15,3 millones para 2015 a USD 33,6 millones para 2016, que representa un incremento del $119.6 \%$ (véase figura 3).

Tabla 4

Colombianos residentes en Argentina en total por grupo de sexos, estado civil, condición de actividad e inactivos (1991-2010)

\begin{tabular}{|c|c|c|c|c|c|c|c|c|c|}
\hline Colombia & \multicolumn{3}{|c|}{1991} & \multicolumn{3}{|c|}{2001} & \multicolumn{3}{|c|}{2010} \\
\hline & \multicolumn{3}{|l|}{2638} & \multicolumn{3}{|l|}{3713} & \multicolumn{3}{|l|}{17576} \\
\hline Grupo de & Hombres & \multicolumn{2}{|c|}{ Mujeres } & Hombres & \multicolumn{2}{|c|}{ Mujeres } & Hombres & \multicolumn{2}{|c|}{ Mujeres } \\
\hline & 1172 & \multicolumn{2}{|l|}{1466} & 1731 & \multicolumn{2}{|c|}{1982} & 8402 & \multicolumn{2}{|l|}{8620} \\
\hline $\begin{array}{l}\text { Estado civil } \\
\quad(+15)\end{array}$ & సँّ & $\begin{array}{l}y \\
y \\
\text { 홀 } \\
\text { 훔 }\end{array}$ & 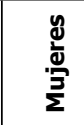 & సँّ & $\begin{array}{l}\text { y } \\
\text { 호 } \\
\text { 호 }\end{array}$ & 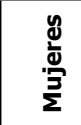 & సँّ & $\begin{array}{l}\text { y } \\
\text { 루 } \\
\text { 호 }\end{array}$ & 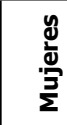 \\
\hline Solteros & 894 & 367 & 527 & 1325 & 640 & 685 & 6644 & 3559 & 3085 \\
\hline $\begin{array}{l}\text { Casados y } \\
\text { unidos }\end{array}$ & 1269 & 573 & 696 & 1664 & 775 & 889 & 7306 & 3310 & 3996 \\
\hline Otros & 191 & 74 & 117 & 315 & 104 & 211 & 471 & 122 & 349 \\
\hline $\begin{array}{l}\text { Condición } \\
\text { de actividad } \\
(+15)\end{array}$ & ङ艹 & $\begin{array}{l}\text { y } \\
\text { 혼 } \\
\text { है } \\
\text { 오 }\end{array}$ & $\begin{array}{l}\frac{y}{2} \\
\stackrel{5}{\Sigma}\end{array}$ & ङ艹 & $\begin{array}{l}\text { y } \\
\text { 호 } \\
\text { Eे } \\
\text { 오 }\end{array}$ & $\begin{array}{l}y \\
\frac{y}{2} \\
\stackrel{5}{\Sigma}\end{array}$ & त्ञ & $\begin{array}{l}\text { yे } \\
\text { ํㅗ } \\
\text { है }\end{array}$ & 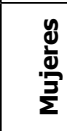 \\
\hline Activos & 1323 & 768 & 555 & 2172 & 1186 & 986 & 10428 & 5474 & 4954 \\
\hline Inactivos & 1053 & 268 & 785 & 1163 & 350 & 813 & 4135 & 1608 & 2527 \\
\hline Inactivos & है & $\begin{array}{l}y \\
y \\
\text { 혼 } \\
\text { 우 }\end{array}$ & 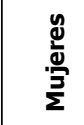 & है & $\begin{array}{l}y \\
\text { dे } \\
\text { है } \\
\text { 우 }\end{array}$ & $\begin{array}{l}y \\
\stackrel{y}{0} \\
\frac{3}{\Sigma}\end{array}$ & है & $\begin{array}{l}y \\
\text { dै } \\
\text { है } \\
\text { 오 }\end{array}$ & $\frac{y}{\stackrel{d}{\Xi}}$ \\
\hline Estudiante & 346 & 120 & 226 & 323 & 162 & 161 & - & - & - \\
\hline $\begin{array}{l}\text { Jubilado o } \\
\text { pensionado }\end{array}$ & 88 & 44 & 44 & 136 & 72 & 64 & - & - & - \\
\hline Otros & 611 & 104 & 507 & 704 & 116 & 588 & - & - & - \\
\hline
\end{tabular}

Fuente: Elaboración propia a partir de información tomada de la Cepal (2016). 
Tabla 5

Colombianos residentes en Argentina económicamente activos por ramas de actividad laboral (1991-2010)

\begin{tabular}{|c|c|c|c|c|c|c|c|c|c|}
\hline \multirow{2}{*}{$\begin{array}{c}\text { Colombia } \\
\text { Actividad laboral }(+15)\end{array}$} & \multicolumn{3}{|c|}{1991} & \multicolumn{3}{|c|}{2001} & \multicolumn{3}{|c|}{2010} \\
\hline & §̋ & $\begin{array}{l}\text { y } \\
\text { है } \\
\text { है } \\
\text { 온 }\end{array}$ & 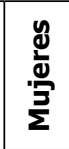 & ग्ञ & $\begin{array}{l}y \\
\text { y } \\
\text { ㄹ } \\
\text { हे } \\
\text { 오 }\end{array}$ & 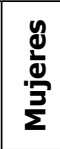 & §̋ँ & 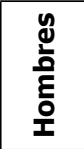 & 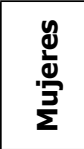 \\
\hline Agricultura, caza, pesca y silvicultura & 38 & 27 & 11 & 21 & 15 & 6 & 70 & 62 & 8 \\
\hline Minas y canteras & - & - & - & 23 & 21 & 2 & 27 & 17 & 10 \\
\hline Industrias manufactureras & 136 & 58 & 78 & 163 & 109 & 54 & 1341 & 833 & 508 \\
\hline Electricidad, gas y agua & - & - & - & 10 & 9 & 1 & 13 & 3 & 10 \\
\hline Construcción & 22 & 22 & 0 & 31 & 28 & 3 & 231 & 193 & 38 \\
\hline Comercio, restaurantes y hoteles & 220 & 111 & 109 & 249 & 160 & 89 & 2005 & 1202 & 803 \\
\hline $\begin{array}{l}\text { Transportes, almacenamiento y } \\
\text { comunicaciones }\end{array}$ & 34 & 25 & 9 & 79 & 52 & 27 & 847 & 432 & 415 \\
\hline $\begin{array}{l}\text { Establecimientos financieros, seguros } \\
\text { y servicios }\end{array}$ & 93 & 70 & 23 & 232 & 126 & 106 & 1556 & 789 & 767 \\
\hline $\begin{array}{l}\text { Servicios comunales, sociales y } \\
\text { personales }\end{array}$ & 634 & 373 & 261 & 842 & 493 & 349 & 3059 & 1413 & 1646 \\
\hline Servicio doméstico & 42 & 0 & 42 & 92 & 3 & 89 & 166 & 32 & 134 \\
\hline
\end{tabular}

Fuente: Elaboración propia a partir de información tomada de la Cepal (2016).

Figura 2

Evolución de las remesas entrantes a Colombia provenientes de Argentina (2005-2016)

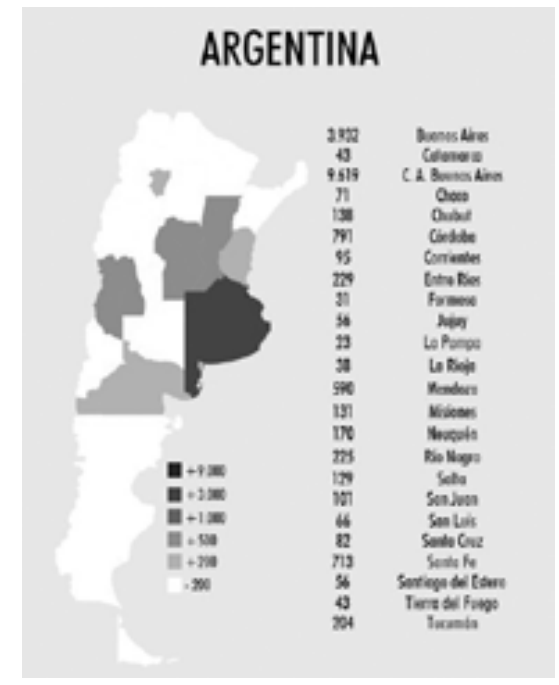

Fuente: Elaboración propia a partir de información del Banco de la República (2017). 
Sin embargo, una de las posibles razones que se dieron para el desarrollo de este fenómeno fue la implementación del cepo cambiario en 2011, que restringía el libre flujo de divisas dentro del mercado argentino que, con una fluctuación de la inflación anual del 20 al 40 \% entre 2010 y 2015 (Cavallo y Bertolotto, 2016, p. 5), generó una fuga de divisas que derivó de una regularización estatal del precio de las divisas. Por tanto, a pesar de que los registros demuestran un significativo crecimiento de la recepción de remesas, no necesariamente obedece a condiciones de mejoría económica o de un progresivo escenario de posicionamiento laboral de los colombianos.

Respecto de los elementos anteriores, es posible mencionar que el avance migratorio de los últimos quince años de la población colombiana en Argentina se ha definido por un proceso de ralentización del crecimiento del número de movimientos, lo cual ha dado a estimaciones de una posible reducción de esta población. Sin embargo, es necesario mencionar el contraste que refleja el sostenimiento las tendencias de los flujos migratorios por concepto laboral y estudiantil entre 2010 y 2015, además del crecimiento exponencial del número de remesas que se han registrado en los últimos tres años. Por tanto, es posible considerar que la población colombiana en Argentina tiende a estar experimentando un escenario de transición económica que ha derivado en un progresivo deterioro de la economía que, con las consecuentes reformas económicas realizadas desde 2015, han derivado en unas condiciones que han sido menos favorables para la proliferación de la migración.

\section{Memorias de plata: perspectivas y experiencias del migrante colombiano en Argentina}

Para complementar el ejercicio realizado, en el que se expone la evolución histórica de las tendencias migratorias de colombianos hacia Argentina, dentro del presente trabajo se pretende exponer una perspectiva más próxima a la experiencia personal de migrar hacia este país. El ejercicio investigativo sobre tal fenómeno versa, no solo sobre un conocimiento grosso modo de las migraciones como una manifestación demográfica que se puede interpretar bajo una multiplicidad de elementos teóricos que contribuyen a la definición de su naturaleza, origen y desarrollo, sino también sobre la comprensión de que este tema puede realizarse desde una visión que tome al migrante como un elemento central para reflejar la realidad de la decisión de tomar nuevos rumbos.

Metodológicamente, a pesar de que el investigador proceda a entender el fenómeno migratorio de cualquier caso alrededor del mundo mediante el uso de herramientas estadísticas, censales y cuantitativas, el estudio etnográfico sobre la perspectiva misma de la experiencia de migrar puede dar una fotografía sobre una ilustración perceptiva de las realidades de esta población. Por ello, a pesar de que el presente trabajo parte del estudio histórico y estadístico del contexto actual de las migraciones colombianas hacia Argentina, vale la pena abordar en este acápite la exposición sobre las diversas vivencias 
y perspectivas sobre esta experiencia de vida como un elemento que cristaliza y fortalece el entendimiento mismo de la realidad de esta población, lo cual conlleva exponer de manera explícita la naturaleza de este fenómeno. Por tanto, para el mencionado ejercicio, se realizaron trabajos de corte etnográfico mediante entrevista semiestructurada, de las cuales se realizaron siete entrevistas en campo entre el 23 de octubre y el 1 de noviembre de 2016, en las ciudades de Buenos Aires, La Plata y Córdoba, locaciones caracterizadas por ser zonas de principal concentración de colombianos en Argentina, con la salvedad de que, si bien la ilustración para realizar está limitada por el número reducido de entrevistas, los autores del presente estudio resaltan la poca despreciable importancia de comprender una forma de lectura de la realidad migratoria de la población colombiana que, a pesar de su dimensión reducida, sus testimonios reflejan una profunda diversidad de dimensiones en las que están inmersos los colombianos dentro de su experiencia de migrar hacia el sur del continente.

En la caracterización de los entrevistados, cabe resaltar que dentro de la muestra la edad de los informantes oscila entre los 21 y 34 años, de los cuales han residido en el país en un tiempo promedio de cinco años, concentrado mayoritariamente en la ciudad de Buenos Aires, manteniendo un orden tendencial a la dispersión territorial expuesta. Dentro de los entrevistados, hay una tendencia unánime a la migración por razones de estudios, aunque difieren los niveles de estudio por razón de nivel, pregrado o posgrado. Asimismo, en las tendencias de estudio del muestreo, se destaca la fuerte predominancia de la tendencia de estudio a humanidades en programas de pregrado y posgrado. Sin embargo, a pesar de esta primera aproximación, las razones de la migración estudiantil obedecen a intereses personales, contextos sociales u otros elementos que inciden directamente en la toma de decisión de dar el paso de migrar al exterior por parte de prospectos de migrantes.

Por tanto, para desarrollar paralelamente un ejercicio de relación entre las tendencias generales de la migración colombiana con las experiencias particulares de los entrevistados, es necesario abordarlas bajo la óptica de escenarios, condiciones y percepciones del migrante a los cuales se enfrenta al llegar a Argentina. En ellas, se busca reflejar elementos como la experiencia de estudio, de buscar un trabajo, del costo de vida, de su experiencia de interacción y adaptación con la sociedad argentina, de su comprensión sobre las condiciones económicas y políticas del país en el momento de la entrevista, entre otros componentes que contribuyen a construir holísticamente la memoria y experiencia de quienes migraron a Argentina. A pesar de que el muestreo es reducido, lo cual no puede ser insumo pleno para una conclusión general del fenómeno, ofrece perspectivas interesantes que describen íntegramente esta experiencia de vida. 
Tabla 6

Caracterización de la población colombiana entrevistada en Argentina

\begin{tabular}{|c|c|c|c|c|c|c|c|c|c|}
\hline & 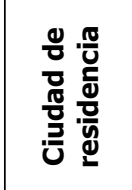 & 茔 & 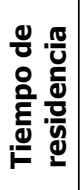 & 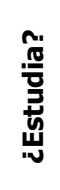 & 营 & 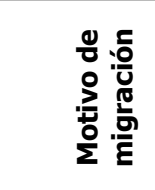 & 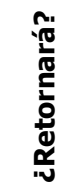 & 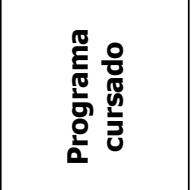 & 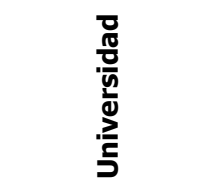 \\
\hline 1 & \begin{tabular}{|l} 
Buenos \\
Aires
\end{tabular} & 24 & $\begin{array}{l}4 \\
\text { años }\end{array}$ & Sí & Sí & $\begin{array}{l}\text { Oferta de } \\
\text { estudios }\end{array}$ & $\begin{array}{l}\text { No } \\
\text { ahora }\end{array}$ & $\begin{array}{l}\text { Ingeniería de } \\
\text { Sistemas }\end{array}$ & $\begin{array}{l}\text { Universidad de } \\
\text { Buenos Aires }\end{array}$ \\
\hline 2 & \begin{tabular}{|l} 
Buenos \\
Aires
\end{tabular} & 28 & $\begin{array}{l}2 \\
\text { años }\end{array}$ & Sí & No & $\begin{array}{l}\text { Oferta de } \\
\text { estudios, } \\
\text { familiar } \\
\text { radicado }\end{array}$ & Sí & $\begin{array}{l}\text { Gestión } \\
\text { Cultural* }\end{array}$ & $\begin{array}{l}\text { Facultad } \\
\text { Latinoamericana } \\
\text { de Ciencias } \\
\text { Sociales }\end{array}$ \\
\hline 3 & $\begin{array}{l}\text { Buenos } \\
\text { Aires }\end{array}$ & 21 & $\begin{array}{l}4 \\
\text { años }\end{array}$ & Sí & No & $\begin{array}{l}\text { Oferta de } \\
\text { estudios, } \\
\text { familiar } \\
\text { radicado }\end{array}$ & No & Psicología & $\begin{array}{l}\text { Universidad de } \\
\text { Buenos Aires }\end{array}$ \\
\hline 4 & \begin{tabular}{|l|} 
Buenos \\
Aires
\end{tabular} & 23 & \begin{tabular}{l|}
5 \\
años
\end{tabular} & Sí & Sí & $\begin{array}{l}\text { Oferta de } \\
\text { estudios }\end{array}$ & $\begin{array}{l}\text { No } \\
\text { ahora }\end{array}$ & Filosofía & $\begin{array}{l}\text { Universidad de } \\
\text { Buenos Aires }\end{array}$ \\
\hline 5 & \begin{tabular}{|l} 
Buenos \\
Aires
\end{tabular} & 26 & \begin{tabular}{l|}
4 \\
años
\end{tabular} & Sí & No & $\begin{array}{l}\text { Oferta de } \\
\text { estudios }\end{array}$ & $\begin{array}{l}\text { No } \\
\text { ahora }\end{array}$ & Filosofía & $\begin{array}{l}\text { Universidad de } \\
\text { Buenos Aires }\end{array}$ \\
\hline 6 & La Plata & 27 & \begin{tabular}{l|}
4 \\
años
\end{tabular} & No & Sí & $\begin{array}{l}\text { Oferta de } \\
\text { estudios }\end{array}$ & Sí & $\begin{array}{l}\text { Historia y } \\
\text { Memoria* }\end{array}$ & $\begin{array}{l}\text { Universidad de } \\
\text { La Plata }\end{array}$ \\
\hline 7 & Córdoba & 34 & $\begin{array}{l}10 \\
\text { años }\end{array}$ & Sí & Sí & $\begin{array}{l}\text { Oferta de } \\
\text { estudios }\end{array}$ & $\begin{array}{l}\text { No } \\
\text { ahora }\end{array}$ & \begin{tabular}{|l} 
Becaria \\
doctoral \\
Centro de \\
Estudios \\
Avanzados
\end{tabular} & $\begin{array}{l}\text { Universidad } \\
\text { Nacional de } \\
\text { Córdoba }\end{array}$ \\
\hline
\end{tabular}

*Programa de estudios de posgrado, maestría o doctorado.

Fuente: Elaboración propia a partir de información recolectada por entrevista semiestructurada.

Por ejemplo, dentro de las múltiples entrevistas, es posible evidenciar una diversidad de razones para la migración, entre ellas, la facilidad en el acceso a la educación, la asequibilidad del costo de vida en Argentina, la proximidad y la gran oferta cultural, entre otros elementos que definen la decisión de migrar y que complementan los estudios tendenciales realizados:

Fue una decisión más por el estudio, porque realmente no podía pagarme un estudio en mi país, en Colombia. Acá, pues, está la oportunidad de estudiar gratis, es una oportunidad, que bueno, esta universidad les abre las puertas a los estudiantes extranjeros. Además, tiene un reconocimiento mundial, el nivel estudiantil es muy bueno, principalmente vine por el estudio y por una oportunidad. (S. Polo, comunicación personal, 23 octubre 2016) 
Porque, en ese momento, lo que yo quería estudiar, que era todo lo relacionado con gestión cultural, acá no estaba muy abierto todavía el campo y tampoco había encontrado ningún programa que me interesara, y los que había eran muy costosos. Entonces, [...] empecé a investigar y encontré que en Argentina [...], en especial Buenos Aires, era un pueblo muy importante a nivel cultural, y que ellos llevaban una ventaja bastante grande en materia de cultura [...] Mi hermana también estaba allá. Había viajado, creo que dos años antes que yo a estudiar. [...] Entonces me di cuenta, aparte de ese proceso, que había muchas oportunidades para hacer muchas cosas, tanto gratis como las cosas que había que pagar, pero, pues, no era tan costoso como, digamos, si quisiera tener acceso a eso acá. (S. Polo, comunicación personal, 25 de octubre de 2016)

Básicamente, porque ningún plan de estudios me convencía en Colombia. Y miré cómo era la cuestión del estudio acá. Y bueno, además que la educación es gratuita, también el plan de estudios de la UBA [Universidad de Buenos Aires] de Psicología me convenció mucho. (S. Polo, comunicación personal, 25 octubre 2016)

Yo tenía la intención desde que me gradué de la universidad de seguir con estudios de posgrado y me parecía que la posibilidad de combinar los estudios de posgrado con una experiencia migratoria era interesante. Por otro lado, [...] también la precarización del acceso a la educación pública (en Colombia), los costos que implica también continuar estudios de posgrado en el sector privado, como ciertas condiciones también que habilitaban, de alguna manera, pensar en un alternativa migratoria para continuar como la formación en términos académicos. Y bueno, también como un impulso un poco aventurero de decir “Bueno, ¿’por qué no vivir en otro lado?” ¿No? Eh, también yo contaba con el apoyo de mis padres, de mi familia, que no es menor para poder emprender un viaje. (S. Polo, comunicación personal, 1 noviembre 2016).

Además de las razones mencionadas que impulsaron a los entrevistados a tomar la decisión de migrar a un destino como Argentina, es posible dilucidar que durante el ejercicio mismo se abordaron temas referentes a su estabilidad laboral, condición que durante los últimos años ha tendido a la inestabilidad gracias a las transformaciones políticas y económicas de los últimos cuatro años. Asimismo, elementos de adaptación como los procesos de filtro del Ciclo Básico Común (CBC) de la Universidad de Buenos Aires (UBA), la convalidación de títulos, entre otros, han sido factores que son condicionantes directos en el desarrollo de una migración estudiantil y laboral, lo cual define la durabilidad de la experiencia migratoria, la tendencia de búsqueda laboral, entre otros elementos que influyen transversalmente al presente análisis: 
Bueno, hay gente que lo toma bien. Gente que lo toma mal. Otra gente, pues, se alegra de que tengamos los extranjeros oportunidad de trabajar. Hay otra gente que lo toma más por el lado de que le estamos quitando un puesto a un argentino, en que en mi puesto debería estar trabajando un argentino y no un extranjero. Lo digo en general. En los hospitales, te dicen lo mismo: ¿́cómo se va a atender a un extranjero, o darle privilegio a un extranjero, y no a un nativo, a un argentino? Entonces, pues mis experiencias como te digo han sido 50/50. (S. Polo, comunicación personal, 23 octubre 2016)

Pues, [...] me parece que sí es bastante competitivo. Y la cuestión es que también tienen una modalidad de trabajo que es muy extraña, que es como para no contratar a alguien fijo. O sea, como que, digamos, te dicen: Ay, sí, bueno, te conocen y como que te dicen: Mira este es el bar, bueno, vas a trabajar acá, no sé, cuatro días. Y después [...] como que el último día que tienes que trabajar antes de que te contraten, supuestamente fijo, te dicen: Bueno, sí, gracias por venir, no sé qué, y después no te llaman más y tú contactas y te dicen: No, están probando a otra persona. Si quieres venir, podemos hablar. (S. Polo, comunicación personal, 25 octubre 2016)

Me parece que, al principio, cuando llegué hace un par de años, era más fácil el tema laboral, había un poco más de oportunidades, había más apertura. Igual, siempre se van a aprovechar del inmigrante, siempre van a intentar pagar menos o hacerlo trabajar más horas [...] Tuve periodos en que no trabajé, que me dediqué, exclusivamente, a estudiar, que no creo que sea la condición de la mayoría de los migrantes que vienen acá. La mayoría vienen, intentan estudiar, pero también tienen que trabajar, terminan solo trabajando y se devuelven. Además, que el tema del filtro del CBC [Ciclo Básico Común] de la UBA [Universidad de Buenos Aires] es un tema que hace que la gente se devuelva muchas veces. (S. Polo, comunicación personal, 25 octubre 2016)

Es bastante complicado para las ciencias humanas, por el tema de la convalidación de los títulos, porque, como bien se sabe, no recibimos la misma formación en ciencias sociales aquí que en Colombia. Son diversas maneras de ver las ciencias sociales. Acá es más disciplinar, nosotros la vemos más global y el tema de la convalidación para poder ejercer es algo complicado, que lleva bastante tiempo. Entonces, en lo laboral, es un poco más complejo. (S. Polo, comunicación personal, 30 octubre 2016)

Ahora bien, es posible ver que en los testimonios de los entrevistados se revalidan las tendencias laborales de los colombianos en Argentina como fuerza laboral enfocada en actividades económicas de prestación de servicios. Considerando los múltiples elementos que definen la experiencia migratoria, se puede evidenciar que existen ocasiones, dentro 
del muestreo de las entrevistas, en las que se enfrentan los migrantes a una reacción adversa por parte de la población argentina, en los que hay casos de rechazo y animadversión sobre el creciente dimensionamiento de la población extranjera en el país. Pero, a pesar de que en los años recientes la migración colombiana ha sido un fenómeno progresivamente familiarizado en la sociedad argentina, también se manifiestan episodios en los que se da un desencuentro personal entre la realidad del migrante con su contexto y la de su descendencia oriunda en Argentina, lo cual es un elemento transfigurador en la vida cotidiana que incide directamente sobre su identidad como migrante:

$\mathrm{Al}$ inicio, bien. Es como todo. Estaba la gente que se alegraba de todo, se alegraba de que estuviéramos aquí, como otra que no. Sí importa mucho la desgracia, lo digo así, del antepasado de nuestro país que, bueno, en principio, Pablo Escobar influyó mucho, las FARC [Fuerzas Armadas Revolucionarias de Colombia], todo. Como que esos temas siempre: Ah, ¿colombiano? Ah, Pablo Escobar, no sé, la droga, siempre se reflejaban mucho en eso o las FARC. Pensaban que había guerra, que éramos narcotraficantes. Pero, como había otra gente que conocía el país o conocía otro colombiano: Ah, hermosas personas. Entonces, dependiendo de las experiencias de esas personas te daban el trato. Entonces hubo mucha gente que me decía: Devolvete a tu país, ¿qué hacés aquí?, como otra gente que como que bienvenido a la argentina, pásala bien, o ¿cómo te han tratado? Dependiendo. (S. Polo, comunicación personal, 25 octubre 2016)

Bueno, pues, por lo general, siempre la gente decía como Ah, un colombiano más. Siempre. Antes de preguntarte qué haces. Primero, por el acento, ya te preguntaban de dónde eres. Tú le decías: De Colombia, y como Ah, un colombiano más, ¿’Por qué hay muchos colombianos aquí en Argentina?, ¿Por qué se vienen tantos colombianos?, siempre, siempre. Y, por lo general, las personas ya mayores siempre te recibían con esa pregunta, como ¿Qué pasa en su país que aquí todos se vienen a estudiar? Entonces les llamaba mucho la atención. Pero sí, siempre la pregunta era esa. De hecho, había hasta comentarios ofensivos [...], una persona también me hizo un comentario como Vas por la calle y levantas una baldosa y salen colombianos como cucarachas, por ejemplo. (S. Polo, comunicación personal, 25 octubre 2016)

Hoy en día, la gente lo tiene superclaro, vas por la calle, te ven y ya saben si eres rolo, paisa, si eres de otro lugar, un argentino solo con verte o con intercambio de un par de palabras contigo. Entonces ya nos conocen y también, [...] la reacción que ellos tienen con nosotros es muy positiva, nos quieren por la música, por la cultura, son fanáticos de la cumbia, tienen su propia versión acá. También, fanáticos de nuestro fútbol; entonces ese tipo de cosas hacen que haya como una relación, siempre hay algo interesante de qué 
hablar con un argentino cuando lo conoces por primera vez, que te quiere preguntar algo. (S. Polo, comunicación personal, 25 octubre 2016)

Bueno, son sociedades, si bien latinoamericanas, con algunos ejes en común, pero bastante diferentes culturalmente. Nosotros somos un poco más o menos, si se quiere un poco más alegres. El argentino es una persona más tranquila frente a muchas situaciones, siempre más relajada, cosa que me ha aportado y ha formado otra persona para mí. Ya vemos la vida, la cotidianidad de otra manera, primero eso [...] Al principio, fue bastante complicado, pero ya nosotros estamos, digamos, un poco más "cancheros" [...] Igual, hay cosas que nos cuestan como, no sé, el hecho de que nosotros como colombianos somos un poco a veces más rencorosos y ellos se enojan y te regañan, y como a los cinco minutos están como si nada contigo. Entonces, uno está en un choque emocional terrible [...] El argentino también es una persona que da mucho, que es muy amiga. No nos podemos quejar, nos han ayudado bastante los conocidos, a sobrellevar, digamos, esa transformación, ese cambio de vida acá. (S. Polo, comunicación personal, 30 octubre 2016)

Yo tengo a mi hija que nace acá, en 2009 [...] Ella tiene ya 7 años, entonces, te imaginarás que he tenido que transitar jardines infantiles, colegios. Y es como también otros espacios donde lo migratorio, la identificación con una figura migrante o extranjera aparece. [...] nunca me voy a olvidar que Juani, muy chiquita, se llama Juana, íbamos en un remís, y me pregunta: Ay, ¿usted de dónde es?, ¿qué es esa tonada? No, de Colombia, de Bogotá, le dije. Y él preguntó: Ah, ¿y ella es argentina o colombiana? Entonces mi hija chiquita le dice: Yo soy Juana (risas) como... iYo soy yo! A mi esa anécdota me hizo reflexionar mucho en torno a cómo construye uno ciertas identidades, cómo pensar también lo transnacional, ¿no?, cómo uno sigue vinculado también a lo colombiano. (S. Polo, comunicación personal, 1 noviembre 2016)

Por último, es interesante revisar la posición del colombiano respecto del entramado político y económico argentino. Dentro del ejercicio de entrevistas realizado, se ha evidenciado una clara perspectiva y posición en cuanto a la actualidad sobre la llegada de Mauricio Macri a la presidencia en 2015. Asuntos como el progresivo recorte a los subsidios al consumo y a los servicios públicos, la inflación, entre otros elementos que han influido directamente en la estabilidad laboral, la capacidad adquisitiva y el costo de vida de los colombianos en este país han sido señalados por los entrevistados como asuntos que dificultan su instalación en el país. A partir de estas situaciones, es posible ver reflejado una auténtica preocupación y una sensación de desmejora de sus condiciones de vida:

Me siento cómodo en el país, pero no me había pasado sentirme incómodo con un Gobierno como me sentía en Colombia, digamos. Y ahora me está pasando con el Gobierno 
de Mauricio Macri. Con Cristina no me pasaba, a pesar de que no fuera fan de Cristina Kirchner, pero me parece que el Gobierno de Cristina Kirchner, por las razones que fuera, se prestó para un montón de avances en educación, en investigación y que nos venía buenísimo a nosotros. Y ahora con el tema de Mauricio Macri me parece que es un retroceso importantísimo y es preocupante la situación. (S. Polo, comunicación personal, 25 octubre 2016)

Luego de pasar por todo esto, creo que se pasó un tiempo mucho más fructífero en comparación con el que está ahora. Yo te digo, cuando yo estaba cursando la maestría y todo esto, el transporte era más barato, había mayor posibilidad frente a lo económico. Ahora, justo este año, sí hemos sentido que se ha vuelto completamente complejo el tema de la inflación, de que es muy caro el transporte, lo que es viajar, de que, por ejemplo, irnos de la capital a la provincia para poder ahorrar algo de dinero y poder estar un poco más cómodos, porque, bueno, esa transición de Gobierno fue, para mí, la sentimos así bastante complicada. (S. Polo, comunicación personal, 30 octubre 2016)

Te contaba anteriormente, con Cristina estaban las cosas como que había mucho, bueno, no digo mucho empleo, pero tenías un poco más de oportunidad al empleo. Había mucha ayuda del Gobierno hacia el pueblo. Pero ahora con este tipo, con Macri, con el presidente Macri, ha disminuido mucho el trabajo. Estuve afectado, me afectó eso. En la empresa que estaba trabajando me despidieron, pero fue por cuestión del Gobierno, porque trabajaba para una entidad que estaba directamente conectada con el Gobierno. Estuvo afectada y tuvo que despedir muchos empleados, entre esos, estuve yo. (S. Polo, comunicación personal, 23 octubre 2016)

Del anterior ejercicio, se desprende la posibilidad de entender la visión que tiene el colombiano sobre los elementos que lo rodean en su entorno social y económico en Argentina. Al escuchar las voces de los entrevistados, es claro evidenciar que no es un periodo con las mismas facilidades para estabilizarse laboralmente o poder subsistir económicamente como las tuvieron años atrás. El deterioro económico, el desempleo, el aumento del costo de vida, la polarización política, entre otros elementos, han dibujado un panorama complejo para los migrantes. Sin embargo, a pesar de estos escollos, la experiencia de migrar a Argentina tiende a ser positiva, gracias a la multiplicidad de factores que pueden ser tan generales como la accesibilidad a la educación superior y la proximidad lingüística, como pueden ser tan particulares como el hecho de haber tenido hijos en Argentina, la recomendación de familiares a migrar a este destino o, incluso, la experiencia de vida que puede ofrecer vivir en una ciudad como Buenos Aires. 


\section{Conclusiones}

Después del anterior ejercicio de revisión histórica, estadística y etnográfica del fenómeno estudiado en el presente trabajo, es posible mencionar que las migraciones colombianas en Argentina son un fenómeno en transición de data reciente a media, en el que durante un periodo de veinticinco años experimentó su punto máximo entre 2001 y 2010, acorde con un avance de la tercera ola migratoria colombiano, en paralelo con una transformación de la política migratoria argentina en las administraciones Kirchner. De ahí que su principal tendencia migratoria ha sido la de orden educativo o estudiantil, en la que la asequibilidad a la educación superior ha sido un incentivo real para el auge de este fenómeno. Además, por la naturaleza del principal motivo de desplazamiento, la tendencia laboral de la población colombiana en Argentina ha obedecido a ser migraciones de corto plazo, lo cual define también la corta durabilidad de los periodos de trabajo de los colombianos en rubros definidos por ser de actividades económicas enfocadas en los servicios como el comercio, el turismo, los servicios personales y comunales, entre otros.

Sin embargo, es de gran importancia mencionar que, tras el estudio de las percepciones de los migrantes colombianos entrevistados sobre su experiencia de vida de vivir en Argentina y de adaptarse a su sociedad y cultura, el migrante colombiano busca asimilarse como un elemento benigno para la sociedad que lo acoge, a pesar de su similitud social distante. En esos testimonios, manifiesta el gran alivio de poder acceder a una educación profesional, de poder construir un proyecto de vida a pesar de los embates circunstanciales. Sin embargo, para los autores de este artículo, el fenómeno migratorio hacia Argentina es, junto con casos como el de la migración hacia Chile, una de las grandes evidencias de una transformación profunda de las tendencias de migración tradicional de los colombianos; actividad que ha construido su lugar durante los últimos cincuenta años de historia nacional, y que ha evolucionado paralelamente con una multiplicidad de evoluciones y cambios políticos, constitucionales, económicos y sociales que han incidido, no solo en la vida de los colombianos, sino también en la evolución misma de las migraciones. La aparición de este destino es, junto con las demás nuevas tendencias, evidencia fehaciente de una nueva perspectiva del colombiano sobre su destino y, por qué no, de la perspectiva del mundo sobre el colombiano.

\section{Agradecimientos}

Los autores agradecen a Nicolás Polo, Diana Arévalo, Verónica Ortiz, Cristian Ortiz, Jacob Palomo, Luisa Heredia, Janneth Clavijo, Carlos Velázquez, Jaime Prada, Ángela Mora, Katherine Cardozo, Susana Jiménez, Laura Granados, Carolina Bernal-Márquez, Francelly Triana y a Laura Manrique por su colaboración para la realización de este artículo. La presente investigación se realizó en el marco del Semillero de Migraciones Colombianas al Exterior de la Universidad del Rosario. 


\section{Referencias}

Alto Comisionado de las Naciones Unidas para los Refugiados (2015). Evaluación de programas de reasentamiento en Argentina, Brasil, Chile, Paraguay y Uruguay. Recuperado de https://goo.gl/o62bUr

Alto Comisionado de las Naciones Unidas para los Refugiados (2016). Population statistics database. Recuperado de http://goo.gl/YZnXpz

Banco de la República (2017). Remesas. Recuperado de http://goo.gl/WLmq5b

Bethell, L. (coord.) (1991). Historia de América Latina (t. 6, 10 y 15). Bercelona: Crítica.

Cavallo, A. y Bertolotto, M. (2016). Serie completa de inflación de Argentina de 1943 a 2016. Recuperado de https://bit.ly/2JrfDMo

Comisión Económica para América Latina (2016). Investigación de la Migración Internacional en Latinoamérica (IMILA). Recuperado de http://goo.gl/RkVkLf

Comisión Económica para América Latina (2017). Red de Datos para Áreas pequeñas por Microcomputador (Redatam). Recuperado de https://goo.gl/fGIU58

Echeverri Buriticá, M. M. (2005). Fracturas identitarias: migración e integración social de los jóvenes colombianos en España. Migraciones Internacionales, 3(1), 141164. Recuperado de https://bit.ly/2MaxxFd

González Martínez, E. (2009). Buscar un refugio para recomponer la vida: el exilio argentino de los años '70. DEP Deportate, Esuli e Profughe, 11(1), 1-15. Recuperado de https://goo.gl/rA68t5

Instituto Nacional de Estadísticas y Censos(2018). Base de datos REDATAM del Censo 201O. Recuperado de https://bit.ly/2ME13T9

Ley 25.871/2003, de 17 de diciembre, Política Migratoria Argentina. Derechos y obligaciones de los extranjeros. Atribuciones del Estado. Admisión de extranjeros a la República Argentina y sus excepciones. Ingreso y egreso de personas. Obligaciones de los medios de transporte internacional. Permanencia de los extranjeros. Legalidad e ilegalidad de la permanencia. Régimen de los recursos. Competencia. Tasas. Argentinos en el exterior. Autoridad de aplicación. Disposiciones complementarias y transitorias.

Levene, R. (1925). Historia argentina (t. 2). Buenos Aires: J. Lajouane \& Cía.

Maurizio, R. (2006). Migraciones internacionales en Argentina: un análisis de sus determinantes y de su relación con el mercado de trabajo. Buenos Aires: Universidad Nacional de General Sarmiento. Recuperado de https://goo.gl/cmy4nx 
Organización Internacional para las Migraciones (2012a). Perfil migratorio de Argentina. Recuperado de https://goo.gl/aE9WHU

Organización Internacional para las Migraciones (2012b). Panorama migratorio de América del Sur. Recuperado de https://bit.ly/2JHDDOZ

Organización Internacional para las Migraciones (2012c). El impacto de las migraciones en Argentina. Recuperado de https://goo.gl/vLlVOk

Organización Internacional para las Migraciones (2016). La migración colombiana en Argentina. Recuperado de https://goo.gl/OigS7e

Organización de las Naciones Unidas (2017). Total international migrant stock report. Recuperado de https://goo.gl/2tWzpi

Oteiza Gruss, V. I. (2007). El aporte de inmigrantes franceses en el diseño de lojurídico espacial de la joven nación argentina. Ponencia presentada en XXVI Congreso de la Asociación Latinoamericana de Sociología, Guadalajara, México. Recuperado de https://goo.gl/os6uGL

Palma, M. (2015). ¿País de emigración, inmigración, tránsito y retorno? La formación de un sistema de migración colombiano. Revista del Observatorio de Análisis de los Sistemas Internacionales, 21(1), 7-28. Recuperado de http://dx.doi. org/10.18601/16577558.n21.02. 
158 Sebastián Polo Alvis y Enrique Serrano López

\section{Notas}

${ }^{1}$ Artículo de reflexión.

${ }^{2}$ Porcentaje calculado según los registros censales de 2001. 